\title{
Panduan Praktek Klinis dan Clinical Pathway Sebagai Solusi Efisiensi Pembiayaan Diagnosa Hernia Inguinalis, Appendisitis, dan Sectio Caesarea di RSI Gondanglegi
}

\author{
Farida Rozany *, Navis Yuliansyah, Siti J Susilo \\ *Penulis Korespondensi: farida.rozany@gmail.com \\ Rumah Sakit Islam Aisyiyah, Malang, Indonesia

\begin{tabular}{l}
\hline $\boldsymbol{I N D E X I N G}$ \\
\hline Keywords: \\
Efficient; \\
National Health \\
Insurance; \\
Clinical Guideline; \\
Clinical Pathway;
\end{tabular} \\ Clinical Pathway;

\begin{abstract}
A B S T R A C T
Aim of this study are to describing factors inefficient in health insurance program in RSI Gondanglegi especially for operatif procedure. This research was conducted with descriptive analysis method. Starting with the observation in the medical record at diagnosis in the case above, and compare with form details the cost of the patients in the period from the first quarter of 2016. The results obtained financing on medical services and medicines. By making the policy of medical services and medicines for patients health insurance, standards of clinical care, effective communication of team with related units, and an increase in the type of hospital grade is expected to improve the efficiency of implementation in RSIG.
\end{abstract}

Kata kunci: Efisiensi;

$\mathrm{JKN}$; PPK; Clinical pathway;

\begin{abstract}
Tujuan dari penelitian ini untuk mengidentifikasi faktor-faktor dari sumber pembiayaan yang tidak efisien di dalam pelaksanaan Jaminan Kesehatan Nasional di RSI Gondanglegi terutama pada kasuskasus operatif adalah untuk Penelitian ini dilakukan dengan metode analisis deskriptif. Diawali dengan melakukan observasi di status rekam medis pada diagnosis kasus di atas, serta membandingkan dengan form rincian biaya pasien pada periode triwulan I tahun 2016. Hasil didapatkan pembiayaan terbesar pada jasa medis dan obat-obatan. Dengan membuat kebijakan jasa medis dan obat-obatan untuk pasien JKN, standar asuhan klinis, clinical pathway, komunikasi yang efektif dari tim JKN dengan unit terkait, dan peningkatan tipe kelas rumah sakit diharapkan dapat meningkatkan efisiensi dari pelaksaan JKN di RSIG.
\end{abstract}

(C) 2017 JMMR. All rights reserved

\section{PENDAHULUAN}

Rumah sakit adalah suatu institusi penyelenggara pelayanan kesehatan yang merupakan bagian integral dari sistem pelayanan kesehatan yang memberikan pelayanan preventif, kuratif, dan rehabilitatif, berupa pelayanan rawat jalan dan rawat inap serta perawatan di rumah. Hakikat dasar dari penyelenggaraan pelayanan kesehatan di rumah sakit adalah pemenuhan kebutuhan dan tuntutan dari para pemakai jasa pelayanan kesehatan dimana pasien mengharapkan suatu penyelesaian dari masalah kesehatannya. Oleh karena itu pasien memandang bahwa rumah sakit harus lebih mampu dalam hal pemberian pelayanan medik dalam upaya penyembuhan dan pemulihan yang berkualitas, cepat tanggap atas keluhan serta penyediaan pelayanan kesehatan yang nyaman. ${ }^{1}$

Rumah sakit perlu melakukan suatu upaya untuk tetap bertahan dan berkembang mengingat besarnya biaya operasional rumah sakit yang sangat tinggi disertai meningkatnya kompetisi kualitas pelayanan jasa rumah sakit dari pesaing.

Adapun upaya yang harus dilakukan rumah sakit adalah dengan meningkatkan pendapatan dari pasien, karena pasien merupakan sumber pendapatan dari rumah sakit baik secara langsung maupun secara tidak langsung melalui asuransi kesehatan. Oleh sebab itu rumah sakit perlu untuk mempertahankan dan meningkatkan kunjungan pasien dengan menampilkan dan memberikan pelayanan kesehatan yang berkualitas. ${ }^{1}$ Rumah sakit diharapkan dapat berorientasi pada kualitas, sehingga hal ini akan mampu mendapatkan profitabilitas jangka panjang yang diperoleh dari kepuasan pasien. Kondisi demikian membuat rumah sakit harus mulai merubah pola pikir yang berfokus pada patient retention. Tujuan dari program kepuasan pasien harus mempunyai pemahaman dan pengertian yang lebih baik tentang pentingnya kepuasan dan loyalitas pasien, yang akan meningkatkan patient retention. ${ }^{1}$ 
Program Jaminan Kesehatan Nasional (JKN) diluncurkan oleh Presiden Susilo Bambang Yudhoyono pada tanggal 1 Januari 2014. JKN ini adalah program jaminan berupa perlindungan kesehatan agar peserta memperoleh manfaat pemeliharaan kesehatan dan perlindungan dalam memenuhi kebutuhan dasar kesehatan yang diberikan kepada setiap orang yang telah membayar iuran atau iurannya dibayar oleh pemerintah. Program ini diselenggarakan oleh Badan Penyelenggara Jaminan Sosial (BPJS) Kesehatan, yang merupakan perubahan dari PT ASKES. $^{2}$

Berdasarkan peraturan BPJS tahun 2014, peserta JKN dapat dilayani di fasilitas kesehatan yang ada di Indonesia dengan sistem berjenjang, yaitu mulai dari fasilitas kesehatan tingkat pertama sampai fasilitas tingkat lanjutan. Fasilitas kesehatan ini bisa milik pemerintah, pemerintah daerah dan milik swasta yang memenuhi ketentuan BPJS dan bekerjasama dengan BPJS. Fasilitas kesehatan tingkat pertama antara lain; Puskesmas, Praktek Dokter, Praktek Dokter Gigi, Klinik Pratama dan Rumah Sakit Tipe D. Sedangkan fasilitas tingkat lanjutan yaitu; Klinik Utama, Rumah Sakit Umum dan Rumah Sakit Khusus. $^{2}$

Berdasarkan peraturan BPJS Tahun 2014, pembayaran pelayanan kesehatan oleh BPJS ke fasilitas tingkat lanjut dengan menggunakan tarif INA CBG's. Tarif paket INA CBG's adalah sistem pembayaran berdasarkan diagnosa. Dalam pembayaran menggunakan sistem INA CBGs, baik Rumah Sakit maupun pihak pembayar tidak lagi merinci tagihan berdasarkan rincian pelayanan yang diberikan, melainkan hanya dengan menyampaikan diagnosis keluar pasien dan kode DRG (Disease Related Group). Besarnya penggantian biaya untuk diagnosis tersebut telah disepakati bersama antara provider/asuransi atau ditetapkan oleh pemerintah sebelumnya. Perkiraan waktu lama perawatan (length of stay) yang akan dijalani oleh pasien juga sudah diperkirakan sebelumnya disesuaikan dengan jenis diagnosis maupun kasus penyakitnya. $^{3}$

RSI Gondanglegi merupakan rumah sakit swasta di bawah Yayasan Rumah Sakit Islam Gondanglegi. RSIG adalah RS tipe D dengan kapasitas 103 tempat tidur, memiliki visi yaitu menjadikan rumah sakit pilihan utama di wilayah Malang Selatan yang bernuansa islami. Misi dari RSIG adalah melengkapi serta meningkatkan fasilitas pelayanan, meningkatkan kualitas sumber daya manusia, dan meningkatkan pendapatan dan kesejahteraan karyawan.
Berdasarkan data pengamatan yang dilakukan di RSIG, terdapat permasalahan pada pelayanan pasien asuransi Jaminan Kesehatan Nasional (JKN) didapatkan pembiayaan yang belum efisien, terutama pada kasuskasus pembedahan seperti hernia inguinalis, appendisitis akut, dan sectio caesarea. Dampak yang ditimbulkan dari permasalahan tersebut rumah sakit mengalami kerugian pada pembiayaan. Hal ini akan menurunkan keuntungan RSIG dalam pengelolaan pasien tersebut. Faktor-faktor yang menyebabkan belum efisiennya pengelolaan kasuskasus tersebut adalah belum adanya panduan praktek klinis (Jennifer N. Edwards)(Jennifer N. Edwards)(Jennifer N. Edwards)(Jennifer N. Edwards) dan clinical pathway untuk penyakit tersebut, lama hari perawatan pasien yang berbeda-beda, koordinasi antara tim JKN dengan unit terkait yang belum optimal, dan diagnosa yang belum tepat dari Unit Gawat Darurat. ${ }^{4}$

Pembiayaan Jaminan Kesehatan Nasional (JKN) adalah dengan sistem prospektif, artinya rumah sakit akan menerima pembayaran untuk proses pelayanan terhadap pasien dalam jumlah yang telah ditentukan berdasarkan sistem klasifikasi layanan, misalnya berdasarkan kelompok diagnosis kasus bedah. Tujuan dari sistem pembayaran prospektif ini adalah untuk memotivasi penyedia layanan kesehatan, dalam hal ini rumah sakit untuk memberikan perawatan pasien secara efektif dan efisien. Jennifer mengungkapkan bahwa efisiensi dapat terjadi apabila melibatkan seluruh staf dalam proses tersebut termasuk para dokter, pemanfaatan teknologi untuk sistem pelayanan kesehatan, membuat standar pada proses pelayanan, dan melakukan manajemen staf dengan baik untuk mengurangi biaya.

Sistem pembayaran prospektif ditentukan dengan tiga komponen :

a. Standar pelayanan kesehatan rata-rata di daerah tertentu, misalnya biaya operasi rata-rata, perawatan kasus kompleks, dan biaya rawat inap.

b. Standar upah minimum di suatu daerah

c. Faktor pembobotan penyakit melalui sistem kelompok diagnosis atau diagnosis related groups

Ketiga hal di atas menentukan besaran dari tarif pada sistem pembayaran prospektif, oleh karena itu tarif INA CBG's berbeda antara daerah yang satu dengan yang lain. Tarif Indonesian Casemix Based Group merupakan tarif paket pada sistem pembayaran prospektif yang diberlakukan di rumah sakit seiring dengan integrasi program JKN. Menurut Komaryani, Case Base Groups atau CBGs merupakan cara pembayaran perawatan pasien 
berdasarkan diagnosis-diagnosis atau kasus-kasus yang relatif sama. $^{5}$

Standar Akreditasi RS versi Komite Akreditasi Rumah Sakit 2012 menyebutkan pada standar Peningkatan Mutu dan Keselamatan Pasien bahwa rumah sakit harus membuat standar asuhan klinik, hal ini bertujuan untuk :

a. Standarisasi dari proses asuhan klinik di rumah sakit.

b. Memberikan asuhan klinik tepat waktu, efektif dengan menggunakan sumber daya secara efisien.

c. Secara konsisten menghasilkan mutu pelayanan tinggi melalui cara-cara "evidence-based"

Bentuk standar asuhan klinik adalah Panduan Praktek Klinis (PPK) dan clinical pathway, kedua hal tersebut juga berfungsi untuk memastikan adanya integrasi dan koordinasi dari pelayanan dengan mengunakan sumber daya secara efisien. ${ }^{4}$

Clinical pathway dapat didefinisikan sebagai pendekatan multidisiplin yang berbasis waktu yang digunakan untuk membantu pasien-pasien tertentu mencapai luaran positif yang diharapkan. Langkah-langkah dalam pathway seharusnya berlaku bagi sebagian besar pasien untuk suatu luaran yang diharapkan. Kondisi klinis pasien tentulah tidak sama, dan perubahan kondisi klinis pastilah seringkali terjadi, sehingga diperlukan fleksibilitas suatu pathway. Clinical pathway merupakan perangkat koordinasi dan komunikasi bagi para petugas yang terlibat dalam tatalaksana pasien yang sama. Clinical pathway merupakan perangkat bantu untuk penerapan standar pelayanan medik (evidence based clinical practice guideline). ${ }^{6}$

Tujuan dari penelitian ini untuk mengidentifikasi faktor-faktor dari sumber pembiayaan yang tidak efisien di dalam pelaksanaan Jaminan Kesehatan Nasional di RSI Gondanglegi terutama pada kasus-kasus operatif.

\section{METODE PENELITIAN}

Penelitian ini dilakukan dengan metode analisis deskriptif. Diawali dengan melakukan observasi status rekam medis pasien pada diagnosis hernia inguinalis, appendisitis akut, dan sectio caesarea pada periode triwulan I tahun 2016. Melalui kegiatan observasi status rekam medis dilakukan analisa mengenai lama hari perawatan pasien, pemeriksaan penunjang yang dilakukan untuk menegakkan diagnosis tersebut, obat-obatan yang digunakan selama masa perawatan, dan kondisi luka operasi pada pasien.

Dari hasil kegiatan observasi status rekam medis, langkah selanjutnya membandingkan dengan form rincian biaya pasien, untuk mengetahui besaran pembiayaan pada pasien, serta melihat lebih jauh pos pembiayaan yang menghabiskan biaya tertinggi.

\section{HASIL DAN PEMBAHASAN}

Berdasarkan hasil observasi pada status rekam medis pasien didapatkan beberapa hal yaitu :

a. Lama hari perawatan pasien rata-rata untuk kasus appendisitis akut 4-5 hari, kasus hernia inguinalis 4-5 hari, dan sectio caesarea 3-4 hari. Berdasarkan observasi pada status rekam medis pasien, terdapat satu kasus appendisitis akut dengan lama perawatan hingga 6 hari, hal ini disebabkan proses diagnosis di UGD (Unit Gawat Darurat) yang belum tepat, sehingga memperpanjang hari perawatan.

b. Pemeriksaan penunjang yang dilakukan adalah darah lengkap, faktor pembekuan darah (bleeding time dan clotting time), foto thorak, dan ultrasonography (USG) pada beberapa kasus. Pada pemeriksaan penunjang foto thorak, hal ini dilakukan sesuai dengan standar prosedur operasional di RSI Gondanglegi, jika pasien berusia lebih dari 40 tahun akan menjalani operasi, maka dilakukan foto thorak.

c. Obat-obatan yang digunakan pada masa perawatan adalah obat antibiotika, obat antimual dan analgetik. Obat-obatan yang digunakan bervariasi nama dagang, meskipun dengan kandungan sama. Pada kasus sectio caesarea obat-obatan yang digunakan lebih banyak, diantaranya menggunakan obat antikoagulan dan vitamin.

d. Untuk outcome pasien didapatkan bahwa rata-rata pasien pulang dengan kondisi luka operasi yang baik.

Hasil analisis pada form rincian pasien pulang didapatkan beberapa hal : 
Tabel 1. Beban Biaya Pasien

\begin{tabular}{clcccccc}
\hline No. & Pembanding & Hernia Inguinalis & $\mathbf{\%}$ & Appendisitis akut & $\mathbf{\%}$ & Sectio Caesarea & $\%$ \\
\hline 1. & Biaya kamar rawat & Rp. $280.000,00$ & $4 \%$ & Rp. $280.000,00$ & $4 \%$ & Rp. $280.000,00$ & $5 \%$ \\
& inap & & & & & \\
2. & Jasa Visite & Rp. $175.000,00$ & $3 \%$ & Rp. $175.000,00$ & $3 \%$ & Rp. $243.000,00$ & $4 \%$ \\
3. & Biaya obat-obatan & Rp. $2.122 .855,00$ & $32 \%$ & Rp. $2.122 .855,00$ & $32 \%$ & Rp. $2.259 .283,00$ & $40 \%$ \\
4. & Biaya jasa medis & Rp. $3.911 .750,00$ & $59 \%$ & Rp. $3.911 .750,00$ & $59 \%$ & Rp. $2.595 .650,00$ & $46 \%$ \\
5. & Tindakan & Rp. $75.000,00$ & $1 \%$ & Rp. $75.000,00$ & $1 \%$ & Rp. $75.000,00$ & $1 \%$ \\
& keperawatan & & & & & & \\
6. & Jasa dokter UGD & Rp. $35.000,00$ & $1 \%$ & Rp. $35.000,00$ & $1 \%$ & Rp. $35.000,00$ & $1 \%$ \\
7. & Asuhan gizi & Rp. $15.000,00$ & $0 \%$ & Rp. $15.000,00$ & $0 \%$ & Rp. $15.000,00$ & $0 \%$ \\
8. & ECG/Doppler & Rp. $56.500,00$ & $1 \%$ & Rp. $56.500,00$ & $1 \%$ & Rp. $175.000,00$ & $3 \%$ \\
9. & INA CBG's & Rp. $3.008 .900,00$ & - & Rp. $2.195 .100,00$ & - & Rp. $3.656 .500,00$ & - \\
\hline Sil
\end{tabular}

Sumber : Hasil Analisis, 2016

Tabel 1 menjelaskan bahwa beban terbesar dalam pembiayaan sebesar 46\%-59\% adalah pada biaya jasa medis dokter, beban kedua sebesar $32 \%-40 \%$ adalah pada obat-obatan, obat-obatan ini adalah termasuk obat-obatan pada masa perawatan dan obat untuk pembiusan. Beban biaya yang lain tidak besar hanya sekitar $1 \%$ yaitu biaya kamar rawat inap, jasa dokter UGD, pemeriksaan ECG, dan asuhan gizi, kemudian diikuti beban biaya sekitar 3\% pada jasa visite dokter. Sehingga beban kerugian untuk masingmasing kasus yang ditanggung RSIG sebesar 40\%-50\% dari total pembiayaan di RSIG.

Penelitian Budiarto dan Sugiarto memberikan bukti bahwa biaya klaim rawat inap menurut INA-CBGs untuk penyakit katastropik di kelas A lebih tinggi dibandingkan dengan semua rumah sakit. Pada penelitian tersebut juga disebutkan bahwa biaya klaim INACBGs lebih besar $14.39 \%$ dibandingkan dengan biaya menurut tarif rumah sakit baik rumah sakit kelas A,B dan RS Khusus. Komponen biaya paling banyak dikeluarkan dari biaya klaim adalah biaya obat (11-31\%), biaya akomodasi (7$26 \%)$, tindakan ruangan $(8-32 \%)$ dan pemeriksaan laboratorium (6-19\%). Jadi diharapkan pada kasus rawat inap ada pemilahan dalam pemeriksaan penunjang dan obat-obatan, agar hal-hal tersebut tidak menjadi cost driver yang besar dalam pembiayaan pasien. ${ }^{2}$ Sumber pembiayaan total dari pasien terdiri dari biaya kamar, pemeriksaan diagnosis, biaya operasi, obat-obatan, nutrisi, biaya visite dokter dan konsultasi, serta terapi post operasi. Penilaian tentang outcome dari CP dinilai dari beberapa hal diantaranya adalah lama hari perawatan, angka mortalitas perioperative, dan komplikasi postoperative. ${ }^{7}$ Clinical pathway dibuat oleh suatu tim yang independen yang merupakan gabungan dari berbagai profesi, yaitu dokter, perawat, dan perawat professional di bidang penyakit yang diderita pasien. Pada pasien dengan kasus bedah, clinical pathway dibuat mulai dari perioperative care, post operative care, hingga discharge planning. Hal spesifik yang dimasukkan ke dalam pathway adalah alat drain, obatobatan, kriteria kapan peralatan tersebut harus dilepas, diet pasien, pemeriksaan laboratorium dan radiologi. ${ }^{7}$

Pada penelitian yang dilakukan Geoffrey menyebutkan dampak dari penggunaan CP pada pasien yang dilakukan operasi pankreatoduodenectomy terdapat beberapa kesimpulan bahwa terjadi penurunan biaya total dari $\$ 47,515$ menjadi $\$ 36,627$, lama hari perawatan dari 16 hari menjadi 13 hari, angka mortalitas menurun dari 3\% menjadi $1 \%$, angka readmission yang menurun dari $15 \%$ menjadi $11 \%$. Jadi dapat disimpulkan bahwa penggunaan CP memberi dampak positif dalam mutu pelayanan pasien. ${ }^{7} \mathrm{Hal}$ ini sejalan dengan penelitian Nichol yang menyebutkan bahwa dengan adanya clinical pathway maka mengurangi penggunaan sumber daya dan meningkatkan efisiensi pada pembiayaan, terutama apabila digunakan pada kasus-kasus dengan kondisi akut seperti infark myokard akut (IMA). ${ }^{89}$ telah melakukan kajian literatur dengan periode yang sangat panjang, yaitu dari tahun 1983 sampai dengan tahun 2005, untuk mengetahui mekanisme penerapan DRG dan casemix accounting seperti apa yang telah sukses diterapkan di rumah sakit.

Hasil penelitiannya menunjukkan bahwa penerapan DRG dan case-mix accounting di suatu rumah sakit akan sukses jika pihak manajemen rumah sakit mengikutsertakan tenaga medis (seperti dokter) dalam perumusan sistem kontrol manajemen. Sistem ini juga akan berhasil jika implementasi diterapkan secara bertahap dan ada tekanan yang intensif dari manajemen untuk menerapkan sistem tersebut. ${ }^{9}$

Hiren menyebutkan bahwa di dalam sistem pembayaran prospektif, penggunaan clinical pathway juga dapat menurunkan pembiayaan sekitar $11 \%$ pada pasien 
post operatif lutut, hal ini disebabkan karena monitoring pasca operasi yang lebih baik, sehingga masa perawatan di rumah sakit lebih pendek dan penggunaan sumber daya lebih minimal. ${ }^{10}$

Penelitian di Jerman tentang sistem pembayaran prospektif menyebutkan bahwa pada kasus-kasus operatif penggunaan panduan praktek klinis dan clinical pathway dapat membantu efisiensi di dalam penggunaan sumber daya, sehingga rumah sakit dapat survive di dalam era pembayaran prospektif. ${ }^{11}$

\section{SIMPULAN}

Pelaksanaan pembiayaan pasien JKN di RSIG belum efisien disebabkan karena beberapa hal: Belum adanya standar asuhan klinis, karena hal ini berfungsi untuk kendali mutu dan biaya. Standar asuhan klinis berfungsi untuk kendali mutu dan biaya, dengan adanya standar asuhan klinis, maka variasi dari obat-obatan, lama hari perawatan, dan pemeriksaan penunjang bisa berkurang. Revisi kebijakan terkait tarif jasa medis, bahan habis pakai dan obat-obatan untuk kasus hernia inguinalis, appendisitis akut, dan sectio caesarea untuk pasien JKN Jasa medis menyerap pembiayaan sekitar 46\%-59\% dari INA CBG's, hal ini membutuhkan perhatian khusus dari manajemen RSIG untuk membuat kebijakan tentang tarif jasa pelayanan antara pasien umum dan pasien JKN. Perlunya mengoptimalkan komunikasi antara tim JKN dan unit terkait. Komunikasi antara tim JKN dan unit terkait harus selalu dibangun, agar koordinasi ini dilakukan rutin sebulan sekali, untuk menjaring permasalahan yang ada di unit. Peningkatan kelas rumah sakit menjadi tipe C. hal ini diharapkan dengan adanya peningkatan kelas rumah sakit juga akan meningkatkan besaran tarif INA CBG's untuk biaya perawatan pasien.

Beberapa alternatif solusi untuk permasalahan di atas sebagai berikut: Membuat standar dalam asuhan klinis, karena hal ini berfungsi untuk kendali mutu dan biaya. Revisi kebijakan terkait tarif jasa medis, bahan habis pakai dan obat-obatan untuk kasus hernia inguinalis, appendisitis akut, dan sectio caesarea untuk pasien JKN. Mengoptimalkan komunikasi antara tim JKN dan unit terkait. Peningkatan kelas rumah sakit menjadi tipe $\mathrm{C}$, hal ini diharapkan untuk meningkatkan tarif INA CBG's.

\section{DAFTAR PUSTAKA}

1. Putri Asmita W. (2008). Analisis Pengaruh Persepsi pasien tentang Mutu Pelayanan Dokter Terhadap
Loyalitas pasien di Poliklinik Umum Instalasi Rawat Jalan Rumah Sakit Panti Wilasa Citarum Semarang. Thesis : Universitas Diponegoro.

2. Sandra Aulia, S, Dewi Kartika Sari, Arthaingan Mutiha. (2015). Cost Recovery Rate Program Jaminan Kesehatan Nasional BPJS Kesehatan. Jurnal Akuntabilitas, Vol. VIII No 2, Halaman 111 - 120.

3. Badan Penyelenggara Jaminan Sosial Kesehatan (BPJS).(2014). Peraturan BPJS No 1 tentang Penyelenggaraan Jaminan Kesehatan

4. Komite Akreditasi Rumah Sakit (KARS).(2012). Standar Akreditasi Rumah Sakit.Jakarta:KARS

5. Jennifer N. Edwards, SS-C, Aimee Lashbrook.(2011).'Achieving Efficiency: Lessons from Four Top-Performing Hospitals'. Commonwealth Fundotion Publication, Vol. 15, Halaman 1528

6. R,Pinzon.(2009). Clinical Pathway Dalam Pelayanan Stroke Akut : Apakah Pathway Memperbaiki Pelayanan?. Jurnal Manajemen Pelayanan Kesehatan, Vol. 12, No. 1, Halaman 20-23.

7. Geoffrey A. Porter, M, Peter W.T. Pisters, MD, Carol Mansyur, MA, Annette Bisanz, MPH, Kim Reyna, MBA, Pam Stanford, RN, Jeffrey E. Lee, MD, and Douglas B. Evans, MD. (2000). 'Cost and Utilization Impact of a Clinical Pathway for Patients Undergoing Pancreaticoduodenectomy'. Annals of Surgical Oncology,Vol. 7, Halaman 484-489.

8. NG, Walls. (1997). A Critical Pathway for Management For Patients With Acute Chest Pain. Ann Internal Medicine, Vol. 97, Halaman 996-1007.

9. $\mathrm{T}$,Lehtonen. (2007). DRG-based prospective pricing and case-mix accounting - Exploring the mechanisms of successful implementation.Management Accounting Research, Vol. 18, Halaman 367-395.

10. Hiren, P. The Effect of Clinical Pathway in Reducing Length of Stay and Hospital Costs and Improving Functional Outcome in Total Hip and Arthroplasty: A Systematic Review, Thesis MGH Institute of Health Professionals.

11. M.H.Wilke. (2001). Introducing the new DRG-based payment system in German hospitals: a difficult operation? Experience and attempts at a solution from a surgery point of view. HEPAC,Vol. 2, Halaman 7985. 